Original Research Paper

\title{
Decolorization of Six Synthetic Dyes by Fungi
}

\author{
${ }^{1}$ E. Samuel Hartikainen, ${ }^{2}$ Otto Miettinen, ${ }^{1}$ Annele Hatakka and ${ }^{1}$ Mika A. Kähkönen \\ ${ }^{I}$ Department of Food and Environmental Sciences, \\ Division of Microbiology and Biotechnology, P.O. Box 56, Biocenter 1, FI 00014 University of Helsinki, Finland \\ ${ }^{2}$ Botanical Museum, Finnish Museum of Natural History, P.O. Box 7, FI 00014 University of Helsinki, Finland
}

\author{
Article history \\ Received: 29-08-2015 \\ Revised: $10-12-2015$ \\ Accepted: 26-02-2016 \\ Corresponding Author: \\ Mika A. Kähkönen \\ Department of Food and \\ Environmental Sciences, \\ Division of Microbiology and \\ Biotechnology, P.O. Box 56, \\ Biocenter 1, FI 00014 \\ University of Helsinki, Finland \\ Email: mika.kahkonen@helsinki.fi
}

\begin{abstract}
To find out ability of fourteen basidiomycetes and four ascomycetes strains to grow in the presence of synthetic colour dyes and to degrade them, fungi were cultivated on the malt agar plates containing $0.5 \mathrm{~g}$ $\mathrm{kg}^{-1}$ dye, either Remazol Brilliant Blue R, Remazol Brilliant Yellow GL, Remazol Brilliant Orange 3 R, Reactive Blue 4, Remazol Brilliant Red F3B or Reactive Black 5. Fungi representing basidiomycetes were Phlebia radiata (FBCC 43), Tremella encephala (FBCC 1145), Dichomitus squalens (FBCC 312), Physisporinus rivulosus (syn. Obba rivulosa, FBCC 939), Cerrena unicolor (FBCC 387), Pleurotus abieticola (FBCC 517), Phanerochaete velutina (FBCC 941), Agrocybe praecox (FBCC 476), Trametes pubescens (FBCC 735), Pleurotus ostreatus (FBCC 498), Fomitopsis pinicola (FBCC 18), Postia placenta (= syn. Rhodonia placenta, FBCC 112), Gloeophyllum trabeum (FBCC 328) and Piptoporus betulinus (FBCC 1191). Ascomycetes belonged to genera Alternaria (HAMBI 3289), Epicoccum (HAMBI 3291), Fusarium (HAMBI 3292) or Chaetomium (HAMBI 3291). The growth rate of $P$. rivulosus belonged to three highest among the 14 tested basidiomycetes with five dyes, but not in the case of Remazol Brilliant Red F3B containing plates. The growth rate of $A$. praecox belonged to three lowest among the 14 tested basidiomycetes on Remazol Brilliant Blue R, Remazol Brilliant Yellow GL, Remazol Brilliant Red F3B, Reactive Black 5 and malt agar. The growth rate of Chaetomium sp. was the highest among the four ascomycetes on all tested plates. Decolorization was seen with 7 basidiomycetous strains on Remazol Brilliant Blue R, with 7 basidiomycetes on Remazol Brilliant Orange 3 R, with 8 basidiomycetes on Reactive Blue 4 and 11 basidiomycetes on Reactive Black 5 containing plates. T. encephala did not decolorize any of the tested six dyes. Epicoccum sp. and Chaetomium sp. decolorized Reactive Black 5 dye containing plates. None of the fourteen basidiomycetous or four ascomycetes were able to degrade all the tested six dyes.
\end{abstract}

Keywords: Synthetic Dye, Basidiomycetes, Ascomycetes, Biodegradation

\section{Introduction}

Synthetic dyes are widely used in mass production of textiles, food and paper (Pandey et al., 2007). The synthetic dyes have complex chemical structures, which make them persistent against light, water and microbial attack (Saratale et al., 2011). This persistence makes them harmful in the environment. Considerable amounts of synthetic dyes have been released from industrial production and discarded products to the environment.
Ligninolytic basidiomycetous fungi produce different combinations of extracellular oxidoreductive enzymes (laccases, manganese peroxidases, versatile peroxidases and lignin peroxidases), which can degrade natural biopolymers such as lignin and degrade recalcitrant xenobiotic synthetic compounds (Hatakka, 1994; Hatakka and Hammel, 2010). The growth of ascomycetes and basidiomycetes and their extracellular enzyme production are suitable indicators for the environmental health. Synthetic colour dye compounds can decrease the 
growth of fungi and production of extra- and intracellular enzymes, which are needed in biodegradation of xenobiotic synthetic dyes. Some ascomycetes are able to produce extracellular oxidative enzymes (Palonen et al., 2003; Sánchez, 2009). Ascomycetes produce mainly hydrolytic enzymes, which degrade carbohydrates (Hatakka and Hammel, 2010; Rodriguez et al., 1996; Kluczek-Turpeinen et al., 2003). Because the variety of different dyes is enormous, only little is known about capabilities of lignocellulose degrading ascomycetes (molds) while the capabilities of lignin degrading wood and litter decomposing basidiomycetes to degrade synthetic dyes have gained interest during last decades (Wesenberg et al., 2003, Rodriguez Couto, 2009). Especially fungal laccases have been studied in larger screenings for bleaching of synthetic dyes.

The aim of the study was to assess the ability of taxonomically and functionally different fungi to grow in the presence of synthetic dyes and to degrade them as indicated by decolorization. We selected fourteen basidiomycetes and four ascomycetes. The selected six synthetic dyes were Remazol Brilliant Blue R, Remazol Brilliant Yellow GL, Remazol Brilliant Orange 3 R, Reactive Blue 4, Remazol Brilliant Red F3B and Reactive Black 5.

\section{Materials and Methods}

The four litter-decomposing saprotrophic ascomycetes from different genera were an Alternaria sp. (HAMBI 3289), an Epicoccum sp. (HAMBI 3291), a Fusarium sp. (HAMBI 3292) and a Chaetomium sp. (HAMBI 3291) deposited to the microbial culture collection HAMBI of the Department of Food and Environmental Sciences, Microbiology and Biotechnology Division, University of Helsinki, Finland. These fungi were isolated from straw, which was buried during winter time in arable soil in Southern Finland. The buried straw was surface-sterilized using $70 \%$ ethanol and $2 \%$ hypochlorite. The surfacesterilized straw was placed on agar plates, which contained 2\% (w/v) Malt Extract (MEA). Isolated fungi were maintained as pure culture on $2 \%$ MEA. Pure cultures were identified morphologically under an optical microscope. Pure cultures selected for this study were stored on $2 \%$ MEA in glass tubes at $4{ }^{\circ} \mathrm{C}$.

Fourteen wood-rotting or litter-decomposing basidiomycetes were selected for this study from the Fungal Biotechnology Culture Collection (FBCC) at the Department of Food and Environmental Sciences, Microbiology and Biotechnology Division, University of Helsinki, Finland. The strains were Phlebia radiata (FBCC 43), Tremella encephala (FBCC 1145), Dichomitus squalens (FBCC 312), Physisporinus rivulosus (= Obba rivulosa, FBCC 939), Cerrena unicolor (FBCC 387), Pleurotus abieticola (FBCC 517), Phanerochaete velutina (FBCC 941), Agrocybe praecox (FBCC 476), Trametes pubescens (FBCC 735), Pleurotus ostreatus (FBCC 498), Fomitopsis pinicola (FBCC 18), Postia placenta (FBCC 112), Gloeophyllum trabeum (FBCC 328) and Piptoporus betulinus (FBCC 1191). These fungi were maintained on $2 \%(\mathrm{w} / \mathrm{v})$ malt extract agar.

\section{Colour Dye Plate Tests}

The ability of fungi to grow and biodegrade synthetic colour dyes were tested with six different dyes. These were Remazol Brilliant Blue R, Remazol Brilliant Yellow GL, Remazol Brilliant Orange 3 R, Reactive Blue 4, Remazol Brilliant Red F3B and Reactive Black 5. $0.5 \mathrm{~g}$ $\mathrm{dm}^{-3}$ of these colour dyes were added on malt agar plates. The control was malt agar plate without added colour dyes. ABTS (2,2'-azino-bis(3-ethylbenzthiazoline-6sulfonic acid, Sigma-Aldrich, U.S.A.) was used as indicator dye in the malt agar plate to test ability of fungi to produce laccase and other oxidative enzymes. The formation of green colour in the ABTS plate indicates the production of oxidative enzyme(s). The decolorization of the other five dyes indicates degradation of the tested dye compound. A $4 \mathrm{~mm}$ diameter fully grown agar plug from each tested fungus was added to the center of the test plate. All was done as triplicate. Plates were incubated at $25^{\circ} \mathrm{C}$. The diameter of the growth and colour change were measured on each sector of $90^{\circ}$ and averaged over the four sectors of the plate.

\section{Results}

The growth rates of 14 basidiomycetes were tested with Remazol Brilliant Blue R, Remazol Brilliant Yellow GL, Remazol Brilliant Orange 3 R, Reactive Blue 4, Remazol Brilliant Red F3B, Reactive Black 5 and ABTS and without added synthetic dyes on malt agar plates (Fig. 1). All these fourteen fungi, namely $P$. radiata, $T$. encephala, $D$. squalens, $P$. rivulosus, $C$. unicolor, $P$. abieticola, $P$. velutina, A. praecox, $T$. pubescens, $P$. ostreatus, $F$. pinicola, $P$. placenta, $G$. trabeum and $P$. betulinus grew in the presence of all the six selected synthetic dyes and ABTS in the plates. The growth rate of $P$. rivulosus was the highest among the 14 tested basidiomycetes on five different dyes, ABTS plates and malt agar plates, but it was not the case on Remazol Brilliant Red F3B containing plates. The growth rate of $P$. radiata belonged to three highest among 14 tested basidiomycetes on five different colour dye and malt agar plates, but this was not the case on ABTS or Remazol Brilliant Yellow GL containing plates. The growth rate of $A$. praecox belonged to three weakest among the 14 tested basidiomycetes on Remazol Brilliant Blue R, Remazol Brilliant Yellow GL, Remazol Brilliant Red F3B, Reactive Black 5 and on malt extract agar without added dye. 

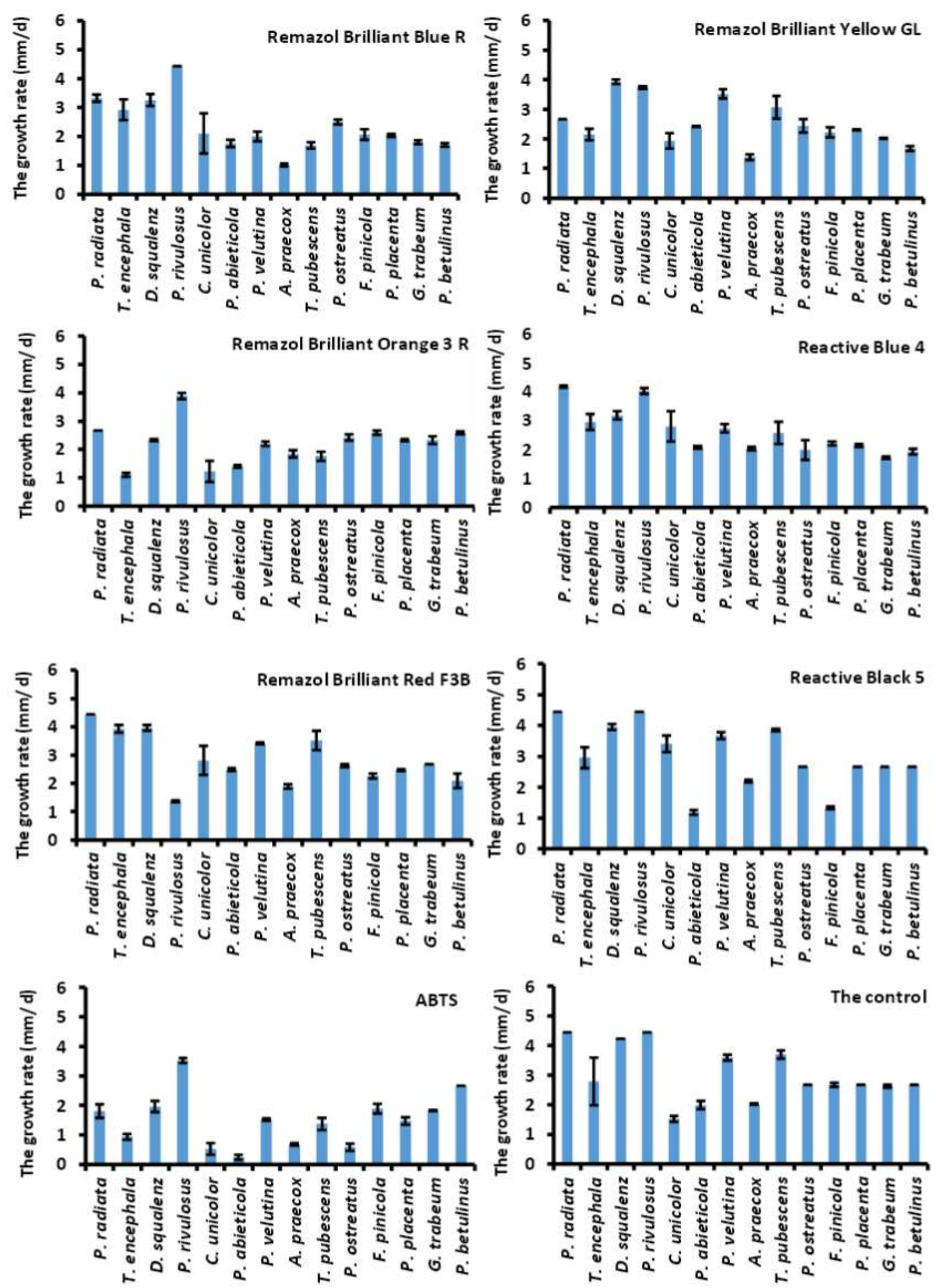

Fig. 1. The growth rate of 14 basidiomycetes on Remazol Brilliant Blue R, Remazol Brilliant Yellow GL, Remazol Brilliant Orange 3 R, Reactive Blue 4, Remazol Brilliant Red F3B, Reactive Black 5 or ABTS containing malt agar plates and the control without added dye 

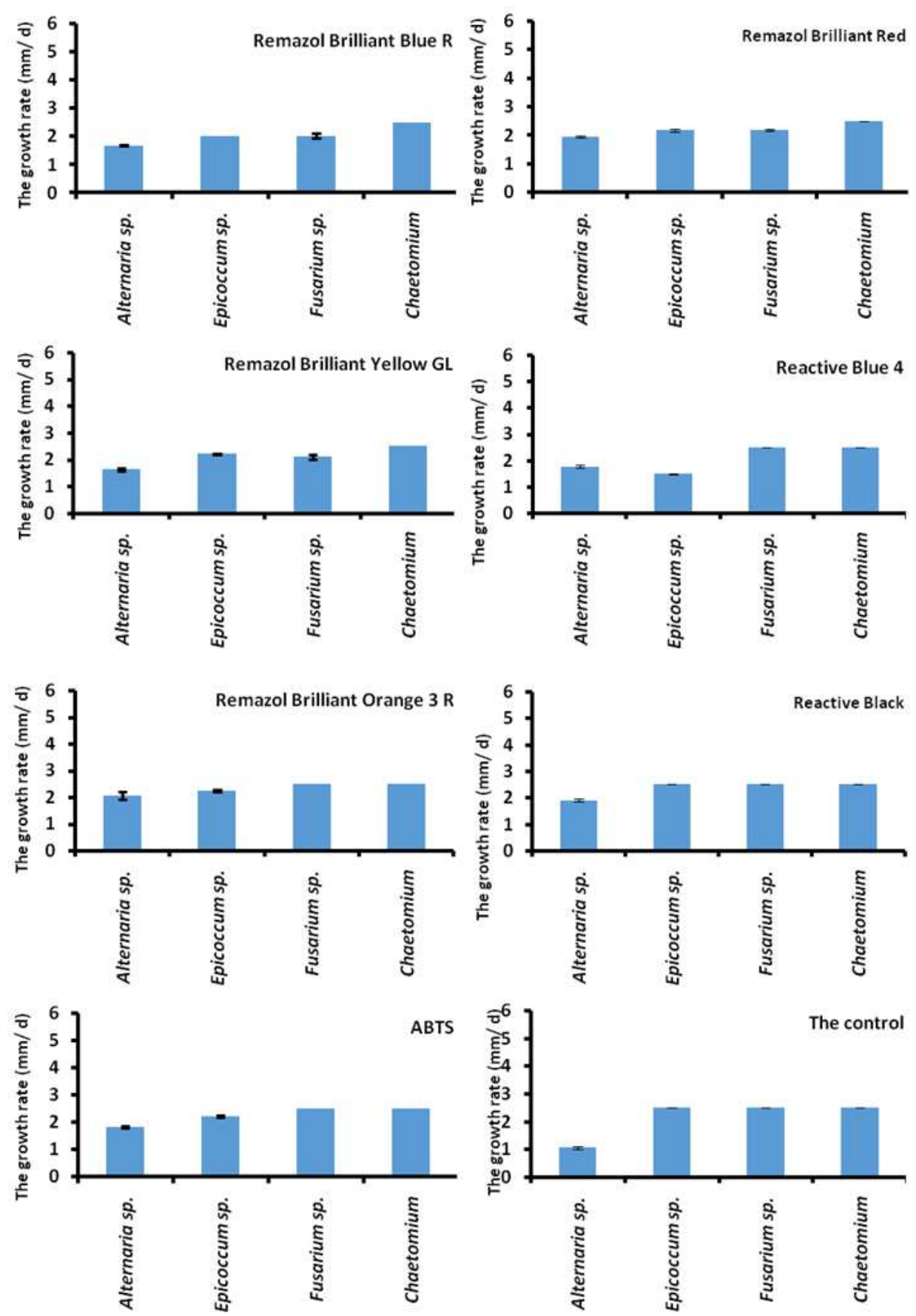

Fig. 2. The growth rate of four ascomycetes on Remazol Brilliant Blue R, Remazol Brilliant Yellow GL, Remazol Brilliant Orange 3 R, Reactive Blue 4, Remazol Brilliant Red F3B, Reactive Black 5 or ABTS containing malt agar plates and the control without added dye

The growth rates of four ascomycetes, namely Alternaria sp., Epicoccum sp., Fusarium sp. and Chaetomium sp., were tested with Remazol Brilliant Blue R, Remazol Brilliant Yellow GL, Remazol Brilliant Orange 3 R, Reactive Blue 4, Remazol Brilliant Red F3B, Reactive Black 5 and ABTS and without added synthetic dyes on malt agar plates (Fig. 2). The growth rate of Chaetomium sp. was the highest among the tested ascomycetes on all tested plates. The growth rate of Alternaria sp. was the lowest among the tested ascomyceteson Remazol Brilliant Blue R, Remazol Brilliant Yellow GL, Remazol Brilliant Red F3B, Reactive Black 5 and ABTS containing plates and malt extract agar plates without added dye. 

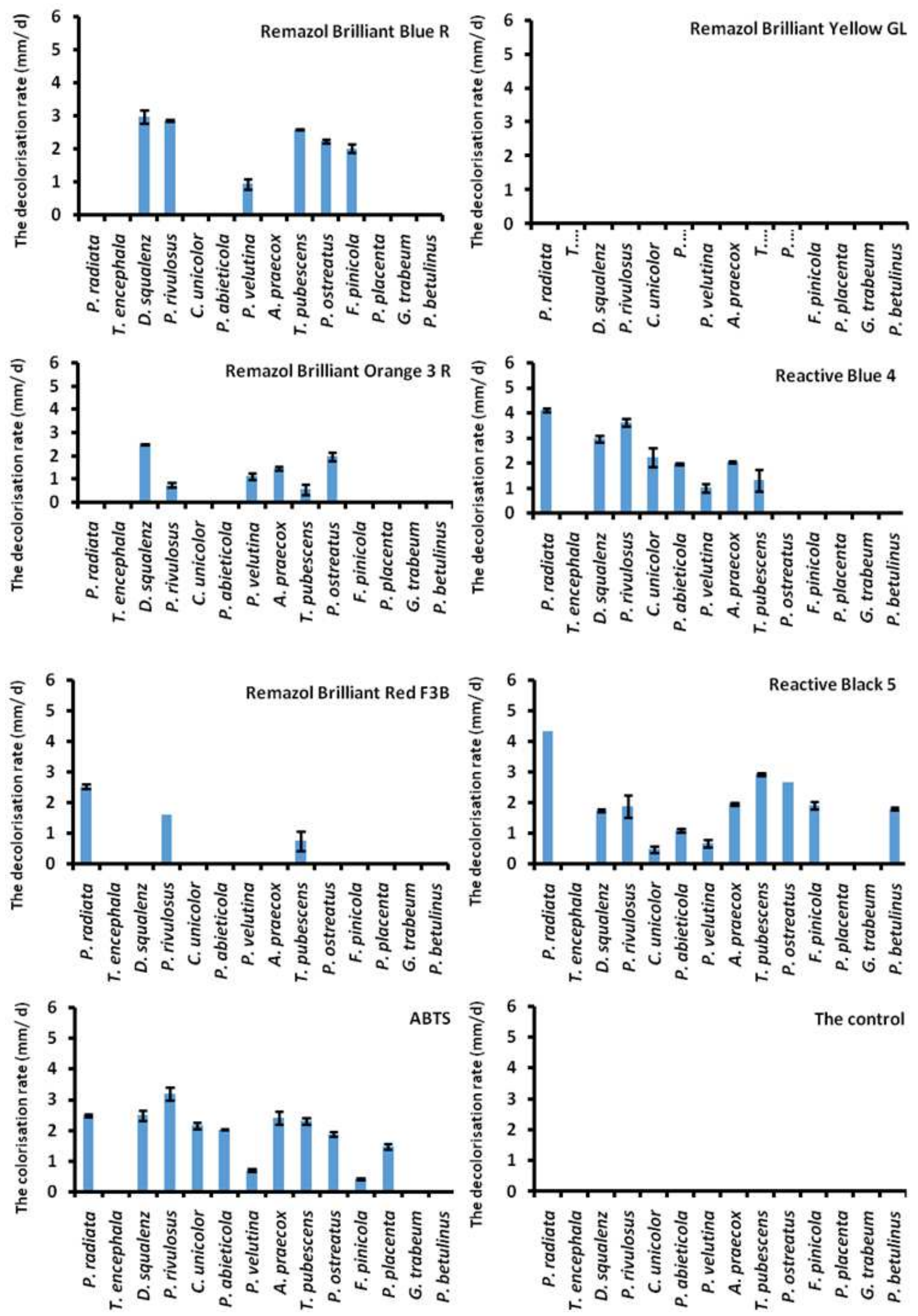

Fig. 3. The decolorization rate with 14 basidiomycetes on Remazol Brilliant Blue R, Remazol Brilliant Yellow GL, Remazol Brilliant Orange 3 R, Reactive Blue 4, Remazol Brilliant Red F3B, Reactive Black 5 and the formation of colour zone with ABTS containing malt agar plates and the control without added dye 
Decolorization was seen with 7 basidiomycetes on Remazol Brilliant Blue R, with 7 basidiomycetes on Remazol Brilliant Orange $3 \mathrm{R}$, with 8 basidiomycetes on Reactive Blue 4 and 11 basidiomycetes Reactive Black 5 containing plates (Fig. 3). D. squalens, P. rivulosus, $P$. velutina and $T$. pubescens decolorized Remazol Brilliant Blue R, Remazol Brilliant Orange 3 R, Reactive Blue 4 and Reactive Black 5. Decolorization was seen with $P$. radiata, $P$. rivulosus and $T$. pubescens on Remazol Brilliant Red F3B containing plates. It is noteworthy that none of the tested fourteen basidiomycetes was able to decolorize Remazol Brilliant yellow GL and as to the other five dyes (Remazol Brilliant Blue R, Remazol Brilliant Orange 3 R, Reactive Blue 4, Remazol Brilliant RedF3B and Reactive Black 5), none of the basidiomycetes was able to decolorize them all. Tremella encephala did not decolorize any of the tested six colour dyes.

Eleven of the tested basidiomycetes, namely the white-rot fungi $P$. radiata, $D$. squalens, $P$. rivulosus, $C$. unicolor, $P$. abieticola, $P$. velutina, T. pubescens and $P$. ostreatus, the litter-decomposing fungus $A$. praecox and the brown-rot fungi $F$. pinicola and $P$. placenta formed colour zone in ABTS plates (Fig. 3) indicating production of extracellular oxidative enzymes, either peroxidases or laccases. The colour zone formation was not seen on ABTS containing plates with T. encephala, $G$. trabeum and $P$. betulinus indicating that these fungi did not produce extracellular oxidative enzymes. Tremella encephala is a fungal parasite and G. trabeum and $P$. betulinus are brown-rot fungi.

The ability of four ascomycetes, Alternaria sp., Chaetomium sp., Epicoccum sp. and Fusarium sp., was tested to decolorize Remazol Brilliant Blue R, Remazol Brilliant Yellow GL, Remazol Brilliant Orange 3 R, Reactive Blue 4, Remazol Brilliant Red F3B, Reactive Black 5 or the formation of colour zone with ABTS containing malt agar plates. The formation of colour zone was seen with Alternaria sp., Epicoccum sp. and Fusarium sp. on ABTS plates indicating production of extracellular oxidative enzyme(s). The formation of colour zone was not seen with Chaetomium sp. on ABTS plates. Decolorization was not seen with any of tested six colour dyes with Alternaria sp. Decolorization was seen with Epicoccum sp. and Chaetomium sp. on Reactive Black 5 dye plates. Decolorization was seen with Fusarium sp. on Reactive Black 5 dye plates.

\section{Discussion}

Our results show that anthraquinone dye Remazol Brilliant Blue R, azo dye Remazol Brilliant Orange 3 R, anthraquinone dye Reactive Blue 4, azo dye Remazol Brilliant Red F3B and azo dye Reactive Black 5 were decolorized by some of the 14 tested basidiomycetes.
None of the tested fungi was able to decolorize all the synthetic dyes in our experiments. Azo dye Remazol Brilliant Yellow GL was not decolorized by any of the 14 tested basidiomycetes. P. ostreatus decolorized well Drimarene Orange K-GL, Procion BluePX-5R and Cibacron Blue P-3RGR in liquid culture during 10 days except Remazol Brilliant Yellow (Asgher et al., 2006). Our results and the results of Asgher et al. (2006) indicate that Remazol Brilliant Yellow GL is persistent in the environment.

Remazol Brilliant Orange 3 R, Reactive Blue 4 and Reactive Black 5 dye were decolorized by $D$. squalens, $P$. rivulosus, $P$. velutina, $A$. praecox and $T$. pubescens indicating that these fungi are potentially useful for biodegradation and bioremediation in multi contaminated soils. Our results showed that Remazol Brilliant Red F3B was decolorized by $P$. radiata, $P$. rivulosus and $T$. pubescens indicating that they could be useful in the treatment of soil or water contaminated by this dye. Earlier it was found that the white-rot fungi Bjerkandera sp., Phanerochaete chrysosporium, T. hirsuta and T. versicolor are able to decolorize Remazol Black B, Reactive Blue 15 and Remazol Brilliant Orange in solid plate during 10 days (Swamy and Ramzay, 1999).

Some of these dyes are commonly used as substrate in enzyme activity assays for different peroxidases. The azo dye Reactive Black 5 (RB5) is used to assay versatile peroxidase activity since this enzyme is able directly oxidize RB5 whereas lignin peroxidase requires the presence of redox mediator such as veratryl alcohol. Typical versatile peroxidases are produced by Pleurotus eryngii (Ruiz-Dueñas et al., 2009). Another strain of $P$. eryngii F032 decolorizes Reactive Black 5 in liquid medium, while producing lignin peroxidase (LiP), manganese peroxidase $(\mathrm{MnP})$ and laccase (Hadibarata et al., 2013), but versatile peroxidase activity was not determined. D. squalens is able to decolorize Orange G, Amaranth, Orange I, Remazol Brilliant Blue R (RBBR), Cu-phthalocyanin, Poly R478, Malachite Green and Crystal Violet on agar plates (Eichlerova et al., 2006). It was reported by Máximo et al. (2003) that Geotrichum sp. is able to decolorize Reactive Black 5, Reactive Red 158 and Reactive Yellow 27. However, the previously isolated Geotrichum sp. Dec-1, which was found to be an efficient dye decolorizing fungus, has been after several re-identifications confirmed to be a strain of the white-rot fungus Bjerkandera adusta (Gomi et al., 2011). B. adusta, Ganoderma sp., Irpex lacteus, Phanerochaete magnoliae, Rigidoporus sp. and Trametes versicolor do not decolorize Reactive Red 158 and Reactive Yellow 27, but these fungi decolorize Remazol Brilliant Blue R (Máximo et al., 2003), which in our experiments was decolorized by $P$. pulmonarius, $P$. rivulosus, $P$. velutina and P. ostreatus. Pleurotus ostreatus (Palmieri et al., 
2005) and Trametes trogii (Mechichi et al., 2006) decolorize Remazol Brilliant Blue R with their laccases. Trametes pubescens decolorizes Reactive Red 243 (azo dye) and Remazol Brilliat Blue R (anthraquinone dye) (Casieri et al., 2008). Our results and the results in literature (Swamy and Ramzay, 1999; Hadibarata et al., 2013; Eichlerova et al., 2006; Máximo et al., 2003; Palmieri et al., 2005; Mechichi et al., 2006; Casieri et al., 2008) show that Remazol Brilliant Blue R, Remazol Brilliant Orange 3 R, Reactive Blue 4, Remazol Brilliant Red F3B and Reactive Black 5 are all decolorized by at least some lignin degrading whiterot basidiomycetes. We conclude that Remazol Brilliant Yellow GL is persistent and can therefore cause harmful impacts in the environment.

Our results from ABTS plate tests indicate that the white-rot fungi $P$. pulmonarius, $P$. radiata, $D$. squalens, $P$. rivulosus, $C$. unicolor, $P$. abieticola, $P$. velutina, $T$. pubescens, $P$. ostreatus, the litter-decomposing fungus $A$. praecox and the brown-rot fungi $F$. pinicola and $P$. placenta produced laccase or other oxidative enzymes. $T$. encephala, G. trabeum and P. betulinus did not produce any extracellular oxidative enzyme (laccase) under our conditions. Recent comparisons of basidiomycete genomes show that the borderline between white-rot and brown-rot fungi is not as strict as previously thought and many brown-rotters such as $F$. pinicola, $P$. placenta and $G$. trabeum do have laccase genes in their genomes (Riley et al., 2014). Laccase is produced by D. squalensis (Susla et al., 2007), P. rivulosus (Hakala et al., 2005), T. pubescens (Palmieri et al., 2000), F. pinicola (Gramss et al., 1999), P. placenta (Wei et al., 2010), P. pulmonarius (De Souza et al., 2004), P. radiata (Arora and Gill, 2001), P. abieticola (Koutrotsios and Zervakis, 2014), $P$. velutina (Boddy, 2000), A. praecox and P. ostreatus (Homolka et al., 2006). Although the studied basidiomycetes $P$. pulmonarius, $P$. radiata, $D$. squalens, $P$. rivulosus, $C$. unicolor, $P$. abieticola, $P$. velutina, A. praecox, T. pubescens, P. ostreatus, $F$. pinicola and $P$. placenta produced laccase, they did not decolorize all studied dyes indicating that other enzymes than laccases were involved in decolorization of the tested dyes. Lignin degrading peroxidases (PODs, Class II peroxidases) produced the white-rot fungi have certainly an important role in the degradation of dyes, but it does not explain the decolorization caused by brown-rot fungi because the most common brown-rot fungi do not produce Class II peroxidases, since there are no POD encoding genes in their genomes (Riley et al., 2014).

All fourteen tested basidiomycetes were able to grow in the presence of all tested six dyes and the redox indicator ABTS. The growth rate of $P$. rivulosus and $P$. radiata belonged to three highest and the growth rate of A. praecox to three lowest among the 14 tested basidiomycetes on Remazol Brilliant Blue R, Remazol Brilliant Yellow GL, Remazol Brilliant Orange 3 R, Remazol Brilliant Red F3B, Reactive Black 5 and on the control malt extract plates without any added dyes. We have previously studied the effect of different metals on the growth of many fungi studied also in the present work. The growth of $A$. praecox was tolerant to $\mathrm{Mn}, \mathrm{Cr}$ and Li (Hartikainen et al., 2013). The growth of $P$. radiata was almost completely inhibited with $2 \mathrm{mg}$ $\mathrm{Co} / \mathrm{kg} \quad(63 \%)$ and with $100 \mathrm{mg} \quad \mathrm{Li} / \mathrm{kg} \quad(88 \%)$ (Hartikainen et al., 2013). The growth of P. rivulosus was sensitive to $\mathrm{Mn}$ (50-400 $\left.\mathrm{mg} \mathrm{kg}^{-1}\right), \mathrm{Cr}$ (20-100 mg $\left.\mathrm{kg}^{-1}\right)$, Cd (5-10 mg kg-1), Li (20-100 $\left.\mathrm{mg} \mathrm{kg}^{-1}\right)$ and Co $\left(20 \mathrm{mg} \mathrm{kg}^{-1}\right)$ (Hartikainen et al., 2013). The growth of $P$. radiata and $P$. rivulosus was sensitive to $\mathrm{Al}$, Mo and $\mathrm{W}$ and tolerant to $\mathrm{Zr}$. The growth was sensitive to $\mathrm{Ga}$ in the case of $P$. radiata and sensitive to $\mathrm{V}$ in the case of $P$. rivulosus (Kluczek-Turpeinen et al., 2014). The growth of the tested ascomycete Chaetomium sp. was sensitive to $\mathrm{Cr}$, Co and $\mathrm{Li}$ and Alternaria sp. to $\mathrm{Cd}$ (Hartikainen et al., 2013). The growth of the ascomycetes Alternaria sp. and Fusarium sp., was sensitive to six metals (Al, Mo, V, Zr, W, Ga) (Kluczek-Turpeinen et al., 2014). Our results showed that $P$. radiata and $P$. rivulosus were fast growing, but the growth of these two fungi is sensitive to several metals (Hartikainen et al., 2013; Kluczek-Turpeinen et al., 2014) indicating that their ability to grow is vulnerable in the metal contaminated waste or soil. Our results indicate that $P$. rivulosus and $P$. radiata are tolerant and suitable for the fast bioremediation of the dyes; namely Remazol Brilliant Blue R, Remazol Brilliant Yellow GL, Remazol Brilliant Orange 3 R, Remazol Brilliant Red F3B, Reactive Black 5 and malt agar plates. The slow growth rate of $A$. praecox was not useful for efficient decolorization of the dyes. The growth rate of Chaetomium sp. was the highest among tested ascomycetes on all tested plates indicating that it was tolerant to all tested dyes. Basidiomycetes were generally more efficient to decolorize dyes than ascomycetes.

\section{Conclusion}

All fourteen selected basidiomycetous fungi $P$. radiata, T. encephala, D. squalens, $P$. rivulosus, C. unicolor, $P$. abieticola, $P$. velutina, A. praecox, T. pubescens, $P$. ostreatus, F. pinicola, P. placenta, G. trabeum and $P$. betulinus grew in the presence of all six selected synthetic dyes and ABTS in the plates. The growth rate of $P$. rivulosus belonged to three highest among the tested basidiomycetes with five dyes, Remazol Brilliant Blue R, Remazol Brilliant Orange 3 R, Reactive Blue 4, Remazol Brilliant Red F3B and Reactive Black 5. The growth rate of Chaetomium sp. was the highest among four ascomycetes on all tested plates. The fast growth rate is beneficial in 
bioremediation of synthetic dye contaminated environment. Remazol Brilliant Blue R, Remazol Brilliant Orange 3 R, Reactive Blue 4, Remazol Brilliant Red F3B and Reactive Black 5 were decolorized with 14 tested basidiomycetes. None of tested fungi was able to decolorize all tested synthetic dyes indicating that abilities of several fungi are needed in the bioremediation of multi contaminated sites. Remazol Brilliant Yellow GL was not decolorized by any of 14 tested basidiomycetes indicating that it is a very persistent dye in the environment.

\section{Acknowledgment}

The study was financially supported by Maj and Tor Nessling Foundation.

\section{Author's Contributions}

E. Samuel Hartikainen: Designed and organized the study, collected the data, performed analysis of the data and wrote the manuscript. fungi.

Otto Miettinen: Gave expert opinions concerning

Annele Hatakka: Gave expert opinions and provided facilities to perform this study.

Mika A. Kähkönen: Designed and organized the study, performed analysis of the data and wrote the manuscript and supervisor in the study.

\section{Ethics}

This article is original and contains unpublished material. The corresponding author confirms that all of the other authors have read and approved the manuscript and no ethical issues involved.

\section{References}

Arora, D.S. and P.K. Gill, 2001. Effects of various media and supplements on laccase production by some white rot fungi. Bioresour. Technol., 77: 89-91. DOI: 10.1016/S0960-8524(00)00114-0

Asgher, M., S.A.H. Shah, M. Ali and R.L. Legge, 2006. Decolorization of some reactive textile dyes by white rot fungi isolated in Pakistan. World J. Microbiol. Biotechnol., 22: 89-93. DOI: $10.1007 / \mathrm{s} 11274-005-5743-6$

Boddy, L., 2000. Interspecific combative interactions between wood-decaying basidiomycetes. FEMS Microbiol. Ecol., 31: 185-194. DOI: 10.1111/j.1574-6941.2000.tb00683.x

Casieri, L., G.C. Varesea, A. Anastasi, V. Prigione and K. Svobodova et al., 2008. Decolorization and detoxication of reactive industrial dyes by immobilized fungi Trametes pubescens and Pleurotus ostreatus. Folia Microbiol., 53: 44-52. DOI: $10.1007 /$ s 12223-008-0006-1
De Souza, C.G.M., K.G. Tychanowicz, D.F. De Souza and R.M. Peralta, 2004. Production of laccase isoforms by Pleurotus pulmonarius in response to presence of phenolic and aromatic compounds. J. Basic Microbiol., 44: 129-136. DOI: 10.1002/jobm.200310365

Eichlerova, I., L. Homolka and F. Nerud, 2006. Synthetic dye decolorization capacity of white rot fungus Dichomitus squalens. Bioresour. Technol., 97: 2153-2159.

DOI: 10.1016/j.biortech.2005.09.014

Gomi, N., S. Yoshida, K. Matsumoto, M. Okudomi and H. Konno et al., 2011. Degradation of the synthetic dye amaranth by the fungus Bjerkandera adusta Dec 1: Inference of the degradation pathway from an analysis of decolorized products. Biodegradation, 22: 1239-1245. DOI: 10.1007/s10532-011-9478-9

Gramss, G., D. Ziegenhagen and S. Sorge, 1999. Degradation of soil humic extract by wood- and soil-associated fungi, bacteria and commercial enzymes. Microbial. Ecol., 37: 140-151.

DOI: $10.1007 / \mathrm{s} 002489900138$

Hadibarata, T., L.A. Adnan, A.R.M. Yusoff, A.R. Yuniarto and M.M.F.A. Zubir et al., 2013. Microbial decolorization of an azo dye reactive black 5 using white-rot fungus Pleurotus eryngii F032. Water Air Soil Poll., 224: 1595-1593.

DOI: $10.1007 / \mathrm{s} 11270-013-1595-0$

Hakala, T.K., T. Lundell, S. Galkin, P. Maijala and N. Kalkkinen et al., 2005. Manganese peroxidases, laccases and oxalic acid from the selective white-rot fungus Physisporinus rivulosus grown on spruce wood chips. Enzyme Microb. Tech., 36: 461-468. DOI: 10.1016/j.enzmictec.2004.10.004

Hartikainen, E.S., A. Hatakka and M.A. Kähkönen, 2013. Impact of cadmium, chromium, cobalt, lithium and manganese to the growth of fungi and production of enzymes. Expert Opin. Environ. Biol., 2: 1-7. DOI: 10.4172/2325-9655.1000109

Hatakka, A. and K.E. Hammel, 2010. Fungal Biodegradation of Lignocelluloses. In: Mycota X Industrial Applications, Hofrichter, M. (Ed.), Springer-Verlag, Berlin, pp: 319-340.

Hatakka, A., 1994. Lignin-modifying enzymes from selected white-rot fungi: Production and role in lignin degradation. FEMS Microbiol. Rev., 13: 125-135. DOI: 10.1111/j.1574-6976.1994.tb00039.x

Homolka, L., L. Lisá and F. Nerud, 2006. Basidiomycete cryopreservation on perlite: Evaluation of a new method. Cryobiology, 52: 446-453. DOI: $10.1016 /$ j.cryobiol.2006.02.003

Koutrotsios, G. and I. Zervakis, 2014. Comparative examination of the olive mill wastewater biodegradation process by various wood-rot macrofungi. Biomed. Res. Int., 2014 : 482937-482950. DOI: $10.1155 / 2014 / 482937$ 
Kluczek-Turpeinen, B., J. Holm, A. Hatakka and M.A. Kähkönen, 2014. Impacts of aluminium, molybdenum, vanadium, zirconium, tungsten and gallium on the growth and enzyme production of ascomycetous and basidiomycetous fungi. Annals Environ. Sci. 8: 39-47.

Kluczek-Turpeinen, B., M. Tuomela, A. Hatakka and M. Hofrichter, 2003. Lignin degradation in a compost environment by the deuteromycete Paecilomyces inflatus. Applied Microbiol. Biotechnol., 61: 374-379. DOI: 10.1007/s00253-003-1272-0

Máximo, C., M.T.P. Amorim and M. Costa-Ferreira, 2003. Biotransformation of industrial reactive azo dyes by Geotrichum sp. CCMI 1019. Enzyme Microb. Technol., 32: 145-151. DOI: $10.1016 / \mathrm{S} 0141-0229(02) 00281-8$

Mechichi, T., N. Mhiri and S. Sayadi, 2006. Remazol Brilliant Blue R decolourization by the laccase from Trametes trogii. Chemosphere, 64: 998-1005. DOI: 10.1016/j.chemosphere.2005.12.061

Palmieri, G., P. Giardina, C. Bianco, B. Fontanella and G. Sannia, 2000. Copper induction of laccase isoenzymes in the ligninolytic fungus Pleurotus ostreatus. Appl. Environ. Microbiol., 66: 920-924. DOI: 10.1128/AEM.66.3.920-924.2000

Palmieri, G., G. Cennamo and G. Sannia, 2005. Remazol Brilliant Blue $\mathrm{R}$ decolourisation by the fungus Pleurotus ostreatus and its oxidative enzymatic system. Enzyme Microb. Technol., 36: 17-24. DOI: $10.1016 /$ j.enzmictec.2004.03.026

Palonen, H., M. Saloheimo, L. Viikari and K. Kruus, 2003. Purification, characterization and sequence analysis of a laccase from the ascomycete Mauginiella sp. Enzyme Microb. Technol., 33: 854-862. DOI: 10.1016/S0141-0229(03)00247-3

Pandey, A., P. Singh and L. Iyengar, 2007. Bacterial decolorization and degradation of azo dyes. Int. Biodeter. Biodeg., 59: 73-84.

DOI: $10.1016 /$ j.ibiod.2006.08.006

Riley, R., A.A. Salamov, D.W. Brown, L.G. Nagy and D. Floudas et al., 2014. Extensive sampling of basidiomycete genomes demonstrates inadequacy of the white-rot/brown-rot paradigm for wood decay fungi. Proc. Nat. Acad. Sci. USA, 111: 9923-9928. DOI: $10.1073 /$ pnas. 1400592111
Rodriguez Couto, S., 2009. Dye removal by immobilised fungi. Biotechnol. Adv., 27: 227-235. DOI: 10.1016/j.biotechadv.2008.12.001

Rodriguez, A., F. Perestelo, A. Carnicero, V. Regalado and R. Perez et al., 1996. Degradation of natural lignins and lignocellulosic substrates by soil-inhabiting fungi imperfecti. FEMS Microbiol. Ecol., 21: 213-219. DOI: 10.1111/j.1574-6941.1996.tb00348.x

Ruiz-Dueñas, F.J., M. Morales, E. Garcia, Y. Miki and M.J. Martinez, et al., 2009. Substrate oxidation sites in versatile peroxidase and other basidiomycete peroxidases. J. Exp. Bot., 60: 441-452. DOI: $10.1093 / \mathrm{jxb} / \mathrm{ern} 261$

Saratale, R.G., G.D. Saratale, J.S. Chang and S.P. Govindwar, 2011. Bacterial decolorization and degradation of azo dyes: A review. J Taiwan Inst. Chem. E, 42: 138-157. DOI: $10.1016 /$ j.jtice.2010.06.006

Sánchez, C., 2009. Lignocellulosic residues: Biodegradation and bioconversion by fungi. Biotechnol. Adv., 27: 185-194. DOI: 10.1016/j.biotechadv.2008.11.001

Susla, M., C. Novotny and K. Svobodova, 2007. The implication of Dichomitus squalens laccase isoenzymes in dye decolorization by immobilized fungal cultures. Bioresour. Technol., 98: 2109-2115. DOI: 10.1016/j.biortech.2006.08.007

Swamy, J. and J.A. Ramsay, 1999. The evaluation of white rot fungi in the decoloration of textile dyes. Enzyme Microb. Technol., 24: 130-137. DOI: 10.1016/S0141-0229(98)00105-7

Wei, D., C.J. Houtman, A.N. Kapich, C.G. Hunt and D. Cullen et al., 2010. Laccase and its role in production of extracellular reactive oxygen species during wood decay by the brown rot basidiomycete Postia placenta. Applied Environ. Microbiol., 76: 2091-2097. DOI: 10.1128/AEM.02929-09

Wesenberg, D., I. Kyriadikes and S.N. Agathos, 2003. White-rot fungi and their enzymes for the treatment of industrial dye effluents. Biotechnol. Adv., 22: 161-187. DOI: 10.1016/j.biotechadv.2003.08.011 